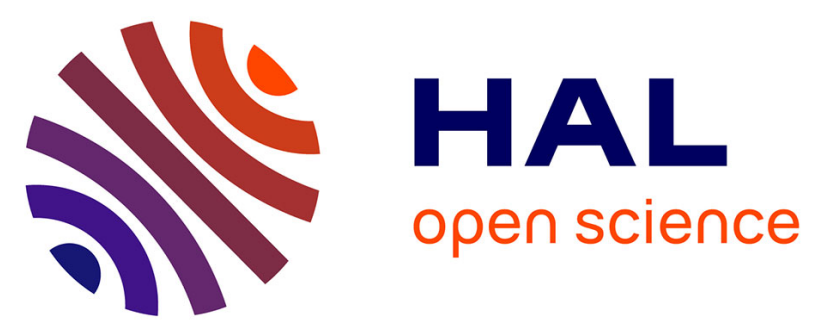

\title{
RICA: A Tracked Robot for Sampling and Radiological Characterization in the Nuclear Field
}

Christian Ducros, Gérard Hauser, Najib Mahjoubi, Philippe Girones, Laurence Boisset, Antoine Sorin, Eric Jonquet, Jean Michel Falciola, Albert Benhamou

\section{- To cite this version:}

Christian Ducros, Gérard Hauser, Najib Mahjoubi, Philippe Girones, Laurence Boisset, et al.. RICA: A Tracked Robot for Sampling and Radiological Characterization in the Nuclear Field. Journal of Field Robotics, 2017, 34 (3), pp.583-599. 10.1002/rob.21650 . cea-02384177

\section{HAL Id: cea-02384177 https://hal-cea.archives-ouvertes.fr/cea-02384177}

Submitted on 28 Nov 2019

HAL is a multi-disciplinary open access archive for the deposit and dissemination of scientific research documents, whether they are published or not. The documents may come from teaching and research institutions in France or abroad, or from public or private research centers.
L'archive ouverte pluridisciplinaire HAL, est destinée au dépôt et à la diffusion de documents scientifiques de niveau recherche, publiés ou non, émanant des établissements d'enseignement et de recherche français ou étrangers, des laboratoires publics ou privés. 


\section{RICA: A tracked robot for sampling and radiological characterization in nuclear field}

\begin{tabular}{|r|l|}
\hline Journal: & Journal of Field Robotics \\
\hline Manuscript ID: & ROB-15-0036 \\
\hline Wiley - Manuscript type: & Regular Article \\
\hline Date Submitted by the Author: & 09-May-2015 \\
\hline Complete List of Authors: & $\begin{array}{l}\text { Mahjoubi, Najib; CEA, DPAD } \\
\text { Girones, Philippe; CEA, DPAD } \\
\text { Boisset, Laurence; CEA, DPAD } \\
\text { Sorin, Antoine; CEA, DPAD } \\
\text { Ducros, Christian; CEA, DPAD } \\
\text { Hauser, Gérard; CEA, DPAD } \\
\text { Jonquet, Eric; CYBERIA, } \\
\text { Falciola, Jean-Michel; CYBERIA, } \\
\text { Benhamou, Albert; CYBERIA, }\end{array}$ \\
\hline Keywords: & extreme environments, emergency response, terrestrial robotics \\
\hline & \\
\hline
\end{tabular}

\section{SCHOLARONE ${ }^{m}$ \\ Manuscripts}




\title{
RICA: A tracked robot for sampling and radiological characterization in nuclear field
}

\author{
Christian DUCROS, Gérard HAUSER \\ CEA, DEN/MAR/DEIM/SEIA \\ BP 17171, 30207 Bagnols-sur-Cèze, France \\ \{christian.ducros, gerard.hauser\}@cea.fr
}

\author{
Najib MAHJOUBI, Philippe GIRONES, Laurence BOISSET, Antoine SORIN \\ CEA, DEN/MAR/DPAD \\ BP 17171, 30207 Bagnols-sur-Cèze, France \\ \{najib.mahjoubi, philippe.girones, laurence.boisset, antoine.sorin \}@cea.fr \\ Eric JONQUET, Jean Michel FALCIOLA, Albert BENHAMOU \\ CYBERIA \\ 55, rue Merlot, 34140 Mauguio, France \\ robert.benhamou@cyberia-robotics.com
}

\begin{abstract}
Throughout the lifetime of nuclear facilities, radiological inspections are of vital importance, as controlling the radiological state of these facilities is necessary to ensure their operations remain safe. This is equally important when under dismantling and decommissioning (D\&D). Inspections of facilities which have contained radionuclides, particularly high and very high activity cells, are the first step when planning to carry out maintenance and D\&D operations. This explains why the development of investigation robots for hostile environments is a strategic approach in the nuclear field in order to meet these needs. The CEA and CYBERIA have worked together to develop the robot RICA (French abbreviation for Robot d'Inspection pour Cellules Aveugles, or blind cell inspection robot) which can locate and measure the activity of radioactive sources. RICA is one of the strategic apparatuses used by the CEA for dismantling operations in its nuclear facilities since 2007. This small tracked robot was developed to offer a good level of modularity in terms of the on-board equipment possible to carry out inspection and sampling missions in extremely hostile environments. To be able to do this, it can be operated either with a complete unit of radiological measurement tools or with a remote-handling arm. The measurement unit consists of a gamma camera, a gamma spectrometer and a dose rate detector. This innovative radiological measurement unit enables in-situ activity quantification and the collection of all the information necessary for interpretation of the radiological spectra. On the other hand, when equipped with a remote-handling arm, the unit is used to carry out samplings, which will then be analyzed in a laboratory. This paper first presents the RICA robot, giving its main technical features. The innovative radiological measurement unit is described, explaining each of its bricks. The gamma irradiator tests which qualified the robot's functioning under irradiation are described and the dose resistance results are analyzed. Lastly, examples of tasks where RICA has been used in CEA nuclear facilities illustrate the robot's modularity.
\end{abstract}




\section{Introduction}

The need to intervene in hostile environments has led to the development of suitably-adapted robotics. As early as the 1950s, the nuclear industry was already working on "intervention" robotics (Bogue, 2011). Such intervention robotics means all the robotized systems which can enable activity on an operation site without direct physical human presence. From the beginning of this industry, the CEA has been working on nuclearadapted remote handling and mobile robotics (Détriché, 1995). Among the many tasks which must be carried out within nuclear facilities, there is one in common to all such plants: radiological characterization (Andrieu et al., 2013). Unlike other work, radiological characterization is necessary throughout all the stages of a D\&D project, from the moment when the final shutdown is under consideration through to the possible decommissioning of a site (Seward and Bakari, 2005). This characterization is also needed after accidents such as those which occurred at the Three Mile Island power plant in 1979 (Moore, 1985) or more recently at the Fukushima Daiichi plant in 2011 (Walker and Wadsworth, 2012). The objective of a characterization process is to carry out a physical and radiological inventory which can be used as a base when planning dismantling projects (Girones et al., 2013). The information collected contributes to a definition of what is commonly called the Initial State, and must enable the identification and understanding of a facility's condition prior to any operations. The radiological investigation step directly impacts the dismantling scenarios, in particular as concerns the quality of the equipment which will have to be deployed. Moreover, accurate knowledge of a facility's radiological state is a key point in guaranteeing an efficient strategy for the management of the waste packages which will be produced. Generally, the information provided by the instrumentation already located in nuclear facilities was gathered in order to monitor production activity. It is usually insufficient to draw up an accurate radiological mapping for the facility when it is being prepared for dismantling. Given the large number of sites to inspect and the long duration (over ten years) of dismantling projects, the use of robots for characterization operations seems an obvious choice, even before taking into account the places where very high level radioactive materials are present or where accidents took place, and in which direct human intervention is not an option. In the latter situations in particular, robots are the only way to obtain the radiological mapping data indispensable for any intervention.

In order to successfully carry out a mapping mission, several issues must be addressed during the development of a specialized robot. Firstly, there is the question of the platform's mobility, which must take into account the environment in which the robot will have to work. In robotics, three main locomotion systems are usually considered: wheels, tracks and legs. Four hybrid system categories can be obtained by combining these main techniques (Bruzzone and Quaglia, 2012). Each locomotion system has strengths and weaknesses, depending on the topology of the environment in which the robot must be operated. Tracked robots have the advantage of being able to cross rough surfaces and pass over obstacles, particularly due to their large track contact surface with the floor. These robots can be classified depending on the number and arrangement of their tracks. Robots with non-articulated tracks (Guarnieri et al., 2009) can be found, as well as those with articulated systems (Yamauchi, 2004), (Morisono, 2013), (Tsukui and Akazawa, 2013), (Nagatani et al., 2013). It should be noted that such articulated track robots have been used to carry out characterization operations to help prepare for the Fukushima Daiichi plant dismantling. As a general rule, these robots were not originally designed for interventions in an irradiating environment and therefore required an intrinsic hardening of their electronic components and sometimes the addition of shielding to overcome the issues related to nuclear conditions. Special attention must always be paid to the irradiation resistance of such robots' electronic components (Nagatani et al., 2011). Another issue concerns the remote handling communication with the intervention robots. In general, a tether is considered the best solution in order to guarantee reliable communication during a task. The structures of nuclear facilities usually rule out wireless means of communication, given the particularly thick concrete walls and sometimes the presence of lead. To the authors' knowledge, wireless communication has never been successfully used for operations in such nuclear situations (Nagatani et al., 2008).

The RICA robot presented in this paper is the result of a partnership between the CEA and the company CYBERIA, and was specifically developed to carry out interventions in irradiating environments (Ducros et al., 2009). The robot has two parallel tracks with a differential steering system. It has been used by the CEA for radiological characterization missions in nuclear facilities undergoing dismantling. To carry out this task, it is equipped with an innovative radiological measurement unit consisting of a dose rate detector, 
a gamma spectrometer and a gamma camera (Le Goaller, 2006), (Lamadie et al., 2006), (Le Goaller and Mahe, 2009). The radiological measurement unit enables the collection of all the radiological data necessary to characterize a facility. Furthermore, to meet a need to take samples or for contact measurements, RICA can be equipped with a suitable remotely-handled arm. Descriptions of the robot and of the radiological measurement unit are given in Sections 2 and 3, respectively. As noted previously, irradiation resistance is an essential point for nuclear applications, and this will be discussed in Section 4. Indeed, to evaluate the RICA robot's irradiation resistance, tests were carried out under gamma irradiation to determine the accumulated doses at the electronic components' failure times. Finally, Section 5 gives examples of tasks carried out by RICA within some CEA facilities. They illustrate the robot's capabilities in terms of radiological characterization and sample collection, as well as contact temperature recording using the remote handling arm.

\section{Mobile platform}

The RICA robot has two sub-assemblies. Figure 1 shows side and front views of the machine. Some of the mobile platform's specifications are given in Table 1. The first lower sub-assembly, the carrier, consists of a

\begin{tabular}{|c|c|}
\hline Mass & $80 \mathrm{~kg}$ \\
\hline Dimensions (L x $\mathrm{l} \times \mathrm{h})$ & $570 \times 420 \times 330 \mathrm{~mm}$ \\
\hline Leaktightness & 2 Bars \\
\hline Material & Inox $316 \mathrm{~L}$ \\
\hline Speed & 0 to $10 \mathrm{~m} / \mathrm{min}$ \\
\hline
\end{tabular}

Table 1: Characteristics of the RICA robot
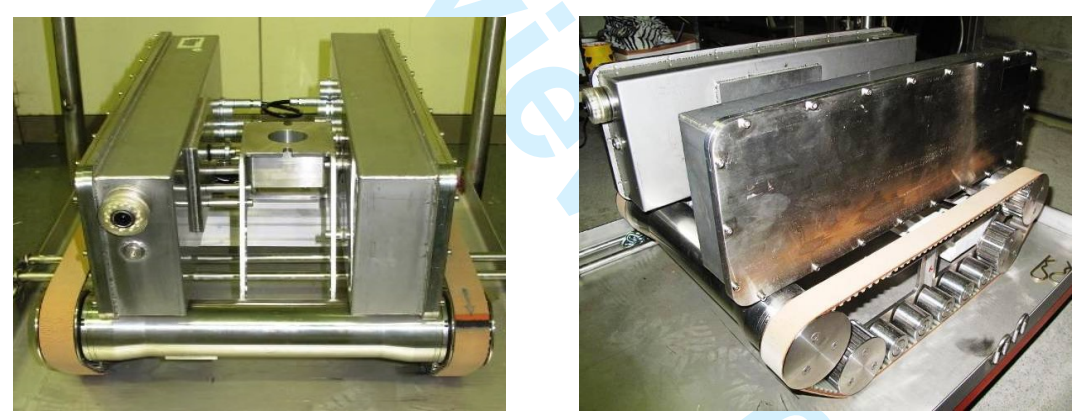

Figure 1: RICA: front view (left) and side view (right)

motorized mechanical base on tracks. Wheels were decided against, as they would not meet the operational requirements under industrial situations. These would involve the RICA robot needing to be able to move over floors with heterogeneous surface conditions, i.e. they could be wet or dry. Moreover, even though a robot on wheels can move at good speeds, its maneuverability remains poor. In comparison, a tracked robot is easier to maneuver even if the speeds it can reach are low. In the context of the sort of application targeted, this does not represent a disadvantage. Polymer tracks were used. They are considered to be one of the RICA consumable items, as it was planned to be able to replace them following an inspection mission to avoid any potential contamination carry-over. The $300 \mathrm{~W}$ motors are powered with 28 volts CC. The upper sub-assembly consists of two cases housing the robot's electronics. One case holds two CCD 1/4" cameras, located at the front and back of the platform, which are used for piloting. Each of the cameras is equipped with a crown of white LEDs in order to obtain usable images during an intervention in a dark environment. This case also houses a motor which enables a gamma camera to be positioned directionally. The second case is essentially used to house the electronic circuits and the means of communication with the exterior. In particular, it has the role of ensuring information multiplexing. 
In order to carry out its two types of missions, i.e. radiological characterizations and sampling, the platform was designed in a modular fashion. This means that depending on the expected mission, the robot can be set up either with a set of radiological measurement tools or else with a remotely-handled arm (see Figure 2). The nuclear instrumentation unit is described in detail in Section 3. The electrical manipulator is a
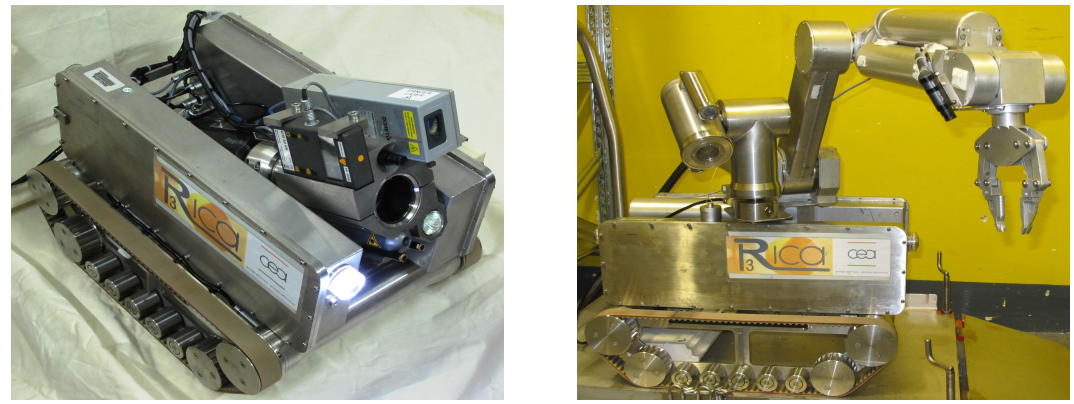

Figure 2: RICA equipped with the radiological instrument unit (left) and with the ROMAIN 50 arm (right)

Romain 50 arm, developed by the CEA and marketed by the company CYBERNETIX (Cybernetix, 2015). It is an arm with seven degrees of freedom, deployable over $1.25 \mathrm{~m}$ horizontally and $2.22 \mathrm{~m}$ vertically. The arm end is fitted with a gripper. The Romain 50 electrical arm is equipped with a site zoom azimuth Bercy model camera commercialized by CYBERIA (Cybéria, 2015). This apparatus is mounted on a support which follows the arm rotation movements and has two adjustable LED lighting systems. It provides the operator with a clear view of the scene, ensuring both improved visual comfort and positioning accuracy. An example of a sampling and clean-up mission in a CEA nuclear facility under dismantling is given in Section 5.1.

The RICA robot weighs $100 \mathrm{~kg}$ when set up for physical and radiological inspection and $90 \mathrm{~kg}$ in the Romain 50 arm configuration. An important feature of this type of machine is the way in which it is connected to the outside. For this project, a tether line was chosen to ensure reliable communication with the robot and for the power supply. Two types of power are in fact necessary: strong, to action the motors and supply the lighting, and weaker, to send back the images and all the measurements. All these aspects are managed via a single hardened coaxial KX4 50 cable which is $100 \mathrm{~m}$ long (Ducros et al., 2009). Consequently, the robot is equipped with an electric coupler for signal multiplexing. Using this multiplexed cable system enables a significant reduction in connection cabling, with only a single cable necessary, and thus avoids handicapping the RICA by forcing it to drag too heavy a weight. The multiplexed signal is transmitted via the coaxial cable to a coupler located outside the worksite. The robot is managed from a piloting station also set up

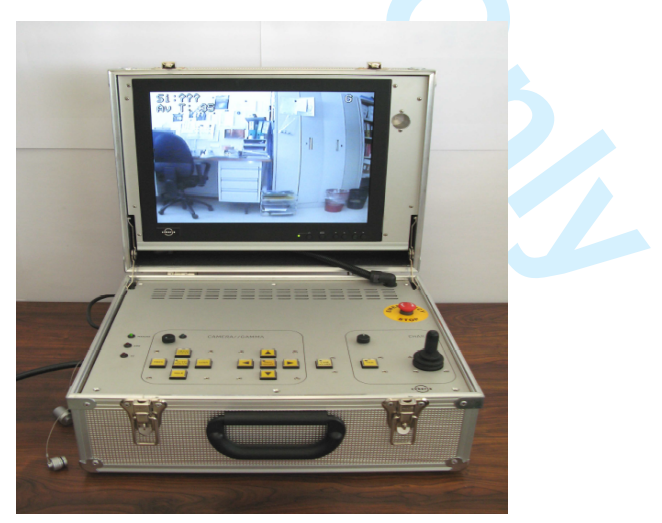

Figure 3: Piloting station

outside the intervention site (Figure 3). It has a joystick controlling backward and forward movements and the left/right orientation of the machine. Press buttons are used to command and permute the front and rear cameras, as well as their lighting systems. The piloting station also positions the gamma camera via two special push buttons. If an incident or a failure should occur, a manual retrieval system is associated to the 


\section{Nuclear instrumentation}

Controlling the radiological quality of a facility is an obligation for a nuclear operator, for obvious safety reasons. This obligation is even higher during the D\&D phase, when after the removal of all recyclable nuclear matter all the technical equipment and fittings in the nuclear zone become classified as waste. The radiological state of the facilities involved is therefore the Initial State for D\&D projects, or in other words, this radiological state is the start point for any D\&D operation. It is the result of the inventory and qualification of what will be the raw material for the waste package production activity and of the facility declassification (Girones et al., 2013). Mastering the source term thus takes on another dimension: it is useful first to define the means and to optimize the clean-up processes, then for the actual dismantling and the conditioning of the nuclear waste produced (Girones et al., 2008). The RICA robot was initially developed to carry out radiological and visual inspections in extreme environments. It meets the need for an initial radiological inventory, then for monitoring the source term in a facility during the D\&D operations. These environments are characterized by high levels of irradiation $\left(>10 m G y \cdot h^{-1}\right)$ and contamination levels of over $10000 \mathrm{~Bq} \cdot \mathrm{cm}^{2}$. The robot's nuclear measurement instrument capability includes gamma camera, dose rate, and gamma spectrometry, offering a complete radiological investigation tool for gamma-emitting radionuclides. The system is suitable for radiological characterization procedures for a site or for industrial equipment which will lead to the drawing up of a map. This cartography involves superimposing physical information, i.e. dimensions, material qualities, and radiological information. The map is drawn up based on the identification of radioactivity concentration points (hot spots), the inventory of the radioelements responsible for the dose rate present, and a report on the dose rate points characterizing the site (ambient dose rate). The RICA nuclear measurement instrument characteristics include:

\section{- Gamma camera}

The center of the acquisition system is occupied by a gamma camera from CANBERRA (Gal et al., 2001). This instrument is used to locate radioactive sources, or "hot spots". The model used has a diameter of $80 \mathrm{~mm}$ and weighs $17 \mathrm{~kg}$. Its mass represents a constraint, but is the inevitable consequence of the need to protect the equipment and the pinhole optics with a dense material, in this case a tungsten alloy $\left(17 \mathrm{~g} . \mathrm{cm}^{-3}\right)$. The acquisition line is built around a scintillator sensitive to gamma rays (Carcreff and Thellier, 1995). The scintillator is kept in darkness by an optical shutter. The "gamma" image obtained by the gamma camera is filtered, and then gives an isocurve representation of the gamma fluence rate. It is next superimposed on the visible image of the scene. The final composite image is used to locate the hot spot dose rates. The energy detection range is $50 \mathrm{keV}-2 \mathrm{MeV}$. 


\section{- Dose rate measurement detector}

Dose rate measurement is useful for the estimation of the radiological quality in the environment in which the gamma camera, and more generally the RICA robot and its equipment, are placed. This information enables the operator to validate the operating conditions. On the one hand, the dose rate is an important parameter for the evaluation of the capture time for a gamma acquisition. The result from a gamma camera is a sum of images, and sensitivity adaptation is ensured by the number of gamma images accumulated. In a first approximation, it is possible to indicate a number of images (VHV, gain, set threshold) for a given ambient dose rate. On the other, the dose rate measurement is taken in order to guarantee the task can be carried out, as the RICA robot has an irradiation limit (Section 4). Dose rate measurement instruments are therefore necessary to predict the equipment's dosimetric integration, and they act as the robot's dosimeter. The portable radiometer used is a 6150 AD5 from Saphymo (Saphymo, 2015). It has a detector sensitive to gamma and X-rays, with a measurement range from $0.1 \mu G y \cdot h^{-1}$ to $1 G y \cdot h^{-1}$. This device was chosen because of its light weight, measurement dynamics, and low sensitivity to temperature $\left(-30^{\circ} \mathrm{C}\right.$ to $\left.50^{\circ} \mathrm{C}\right)$.

- Gamma spectrometer and laser telemeter

Gamma spectrometry and telemetry cannot be disassociated. Gamma spectrometry is used to qualify and quantify gamma emitters, and the data processing of the gamma spectra depends on the position in space of the detector's sensitive zone. The telemeter installed on the robot is a DISTO model from LEICA. This device is placed in order to give the distance between the center of the sensitive detectors and the first object in the robot's alignment axis. The quality of the gamma spectrometry detectors was decided by the mass and the quality of the spectra. The radionuclide qualification depends on the resolution or width halfway up the peaks, and on the yield. As the RICA intervention sites are contaminated by all possible radionuclides, it is essential to have a detector technology with a small width at half-height and a yield which is compatible with the fluence rates recorded. The CdZnTe crystal technology detectors were chosen based on mass and resolution factors. Gamma spectrometry performed by detectors based on CdTe or CdZnTe crystals is relatively recent (Fougeres et al., 1999). It enables gamma emitter radioelements to be identified using compact, cheap detectors adapted to high gamma fluence rates (Lamadie et al., 2007). Initially developed in the context of Infra-red or X imagery, the CdTe technology was further developed at the end of the 1990s to give possibilities for use in gamma spectrometry. The CdTe is a semi-conductor with a $1.47 \mathrm{eV}$ band width (compared to $0.64 \mathrm{eV}$ for $\mathrm{Ge}$ ), enabling it to be polarized at ambient temperature. As the atomic numbers of Cadmium $(\mathrm{Cd})$ and of Tellurium $(\mathrm{Te})$ are respectively 48 and 52 , while Germanium (Ge) is only 32, their probability of gamma ray absorption is greater for a given volume. Currently, industrialists are selling detectors able to be coupled to standard electronics (Inspector, GBS MCA166, etc.) and carried by the RICA robot. Different types of detector were evaluated in laboratory and qualified during in situ operations. They were mainly hemispheric polarization detectors marketed by RITEC. At present, the industrial detectors on the market have probes based on crystals with volumes of between $0.5 \mathrm{~mm}^{3}$ and $1500 \mathrm{~mm}^{3}$. They enable good quality spectra for dose rates of between $1 \mu G y \cdot h^{-1}$ and $10 G y \cdot h^{-1}$ (typically for Cesium-137 or Cobalt-60). At $662 \mathrm{keV}$, the full-width half maximum is between $8 \mathrm{keV}$, for small volume detectors, and $12 \mathrm{keV}$ for large volume detectors $\left(500 \mathrm{~cm}^{3}\right.$ or $\left.1500 \mathrm{~cm}^{3}\right)$. The full-width half maximum criterion is not very well-adapted to this sort of detector, as for charge collection reasons the photo-electric peaks are asymmetrical. Thus the RICA instrumentation subsystem is equipped with a CdZnTe detector from RITEC. The sensitive zone volume is $20 \mathrm{~mm}^{3}$. It is connected to compact analog electronics from GBS, reference MCA166. This device is compact, light and fitted with an RS232 link. The detector is placed in a lead collimator, with a pierced front. This hole acts as collimation and reduces the solid angle to $5^{\circ}$ or $10^{\circ}$ depending on how it is to be used. The lead is $1.5 \mathrm{~cm}$ thick, with an exterior hole diameter of $42 \mathrm{~mm}$. Two "line" lasers form a cross whose intersection passes through the axis of the CdZnTe detector lead collimator.

The originality of the RICA robot measurement unit is that it was designed to carry three radiological measurement tools - a gamma camera, a spectrometer and a dose rate detector (Figure 2, left). The complete set of signals from the three devices is multiplexed. This solution for processing the signals is a valuable 


\section{Gamma-ray irradiation of electronic components}

Irradiation resistance tests were carried out in a gamma irradiator to be sure of the electronic components considered to be sensitive. These irradiation tests reproduce the impact of ionizing energy due to a nuclear facility's charged particles. They were performed in the TRAD bunker (TRAD, 2015) (Figure 6). This bunker houses a panoramic Cobalt-60 source with an activity of 7.4TBq. The gamma beam can give a dose rate of $7 \cdot 10^{-2} G y \cdot h^{-1}$ à $10 G y \cdot h^{-1}$. The bunker temperature is set at $20^{\circ} \mathrm{C} \pm 2^{\circ} \mathrm{C}$. The components to be irradiated are placed facing the gamma source on special supports at a distance to the gamma source enabling the dose rate received by the component to be regulated (Figure 7). The dose rate distribution within the bunker is controlled two ways. First of all, the distribution is simulated by the 3D RayXpert modeling software developed by TRAD (Thomas et al., 2008). The digital model used can take into account the source activity, its location within the area and the bunker geometry. As well as this, the dose rate is checked with SAPHYMO SHI detectors. The total accumulated dose is checked with a DOSElec detector developed by TRAD. Fourteen components were irradiated at different dose rates $\left(3.10 G y . h^{-1}, 2.10 G y . h^{-1}\right.$ et $1.80 G y \cdot h^{-1}$ ). There was a $10 \%$ average variation of the dose rates received by the components during the irradiation. Tables 2, 3 and 4 give the irradiation dose rate and the total doses measured for each of the components, which were the on-board electronic cards, the power supply cables and a camera. The tests used to assess the doses at which failures were observed consisted in measuring the output voltages tensions, the data transmitted by the cards or by the video camera return. It can be seen that there was no card failure for the gamma camera coupler, the HF 2-way coupler, the 12V1A motor amplifier card for total doses of over $1000 G y$. The transvideo power supply card and the $50 \mathrm{~W} 18-36 \mathrm{~V}$ power supply functioned correctly at doses of up to a hundred Grays, whereas the other components were able to resist doses of over 


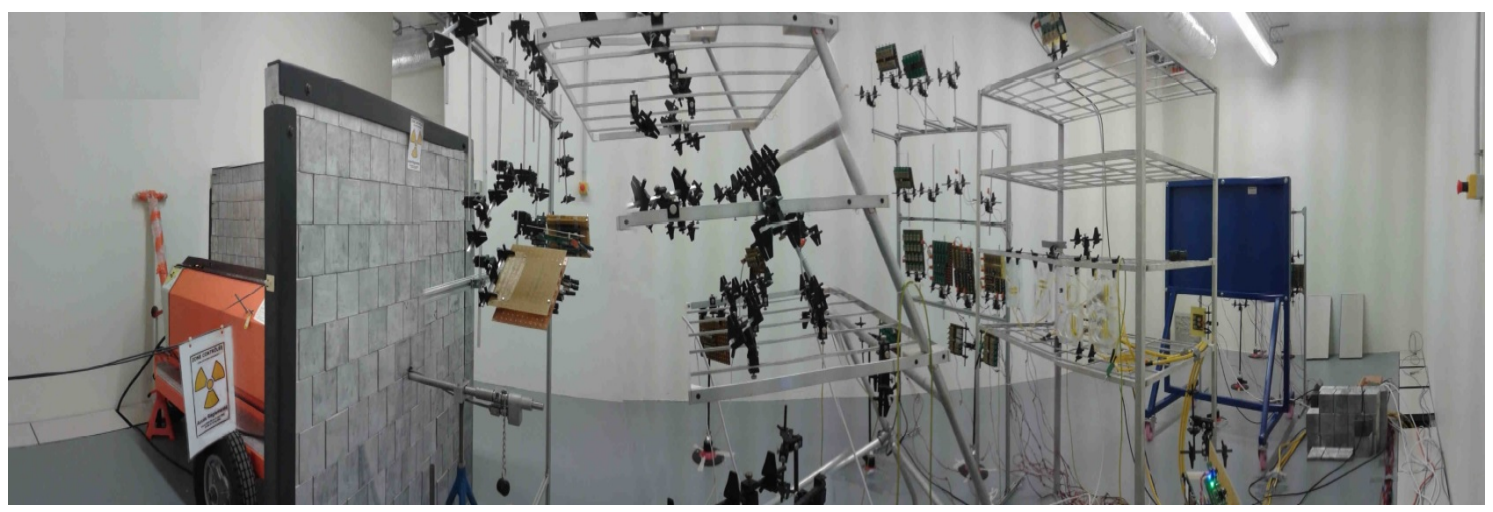

Figure 6: Interior of the gamma irradiation bunker - TRAD
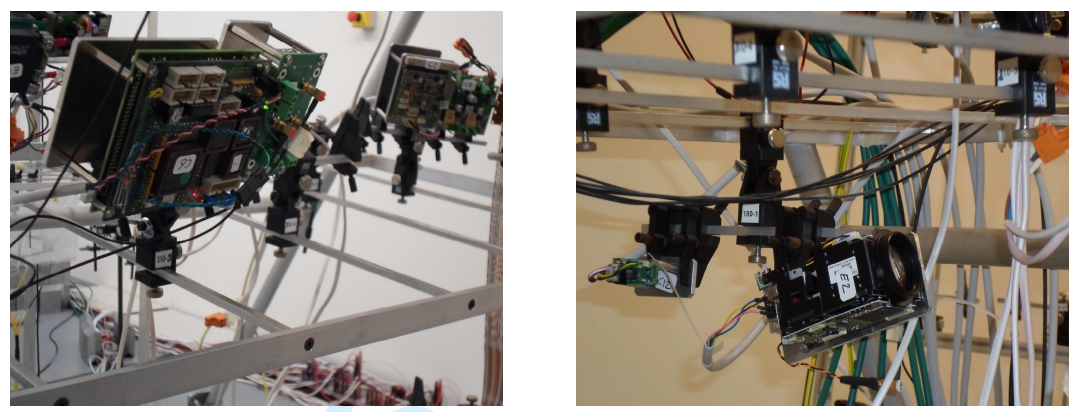

Figure 7: Examples of components positioned for irradiation

\begin{tabular}{|l|l|l|l|}
\hline Equipment & Dose rate $\left(G y \cdot h^{-1}\right)$ & Total dose $(G y)$ & $\begin{array}{l}\text { Dose at moment of } \\
\text { failure (Gy) }\end{array}$ \\
\hline $\begin{array}{l}\text { Modem card } \\
70 \mathrm{MHz}\end{array}$ & 3.19 & 2050 & No failure \\
\hline $\begin{array}{l}4 \text { RS TR card } \\
\text { FREQ1 RS232C }\end{array}$ & 3.46 & 320 & 290 \\
\hline Micro 552 card & 3.46 & 250 & 220 \\
\hline TR4 emission card & 3.46 & 320 & 290 \\
\hline $\begin{array}{l}\text { Gamma Camera } \\
\text { coupler card }\end{array}$ & 3.46 & 2450 & No failure \\
\hline $\begin{array}{l}\text { HF 2-way coupler } \\
\text { card }\end{array}$ & 3.46 & 2360 & No failure \\
\hline $\begin{array}{l}\text { 12V1A Motor am- } \\
\text { plifier card }\end{array}$ & 3.33 & 2130 & No failure \\
\hline
\end{tabular}

Table 2: Results for irradiations at a dose rate of $3.10 G y \cdot h^{-1}$

\begin{tabular}{|l|l|l|l|}
\hline Equipment & Dose rate $\left(G y \cdot h^{-1}\right)$ & Total dose $(G y)$ & $\begin{array}{l}\text { Dose at moment of } \\
\text { failure }(G y)\end{array}$ \\
\hline $\begin{array}{l}\text { Motor amplifier } \\
\text { card }\end{array}$ & 2.18 & 1010 & No failure \\
\hline
\end{tabular}

Table 3: Results for irradiations at a dose rate of $2.10 G y \cdot h^{-1}$ 
200 Gy. These results should be considered with some caution, as they were obtained from a single test on a single component. Obviously, electronic components are likely to have different properties depending on their production lot or indeed their manufacturer (Wolicki et al., 1995). Regarding this topic, it would be necessary to carry out additional tests with sufficient runs to be statistically representative before being able to conclude as to the expected lifetime of these components in an irradiating environment.

\section{Examples of missions}

The missions described in this paper were carried out in the Marcoule Pilot Workshop facility (APM), commissioned in 1962 and operated by the CEA. It was used for studies and developments concerning the retreatment of irradiated fuel assemblies and the vitrification of fission product solutions. The facility was also used as an interim storage site for small-sized blocks of fission product glasses and for various technological wastes. These missions serve as illustrations of the usefulness which the remotely-handled Romain 50 unit (section 5.1) and the radiological measurement unit (section 5.2).

\subsection{Mission of the RICA robot equipped with a Romain 50 arm}

The RICA robot version equipped with a Romain 50 arm was used to carry out sampling or clean-up tasks (Section 5.1.1) or to carry contact detectors within a zone of interest (Section 5.1.2).

\subsubsection{Door threshold clean-up of a waste container storage cell}

The clean-up task took place in a High Activity Level (HL) cell group, which was used to store solutions from fuel retreatment (see Figure 8). The cell contains $\alpha, \beta$ and $\gamma$ particle emitting radionuclides and long-lived intermediate radiation (activation products and actinides). A previously-performed video inspection enabled metallic objects to be seen on the cell door threshold, dating back to the period when the cells were operated. Transfers of waste containers had been planned between two cells concerned prior to the waste removal to specialized waste disposals. The storage cell door would therefore have to be opened and closed many times, and it was necessary to ensure the safety of these operations, especially to avoid the door becoming blocked in the open position. The task consisted of collecting the debris present around the cell door rail and removing it. Most of this mission thus had to be carried out with the cell door open (see Figure 9). The dose rate was $1.9 \mu G y \cdot h^{-1}$ in front of the closed door, and $10 \mathrm{mGy} \cdot h^{-1}$ when the door was open.

To perform this mission, the RICA robot was equipped with the Romain 50 arm and a dose rate measurement detector. A suitable container was adapted to enable it to be carried to the intervention site by the RICA and then used to hold the waste items the robot would collect (see Figure 10). Once the assorted waste 

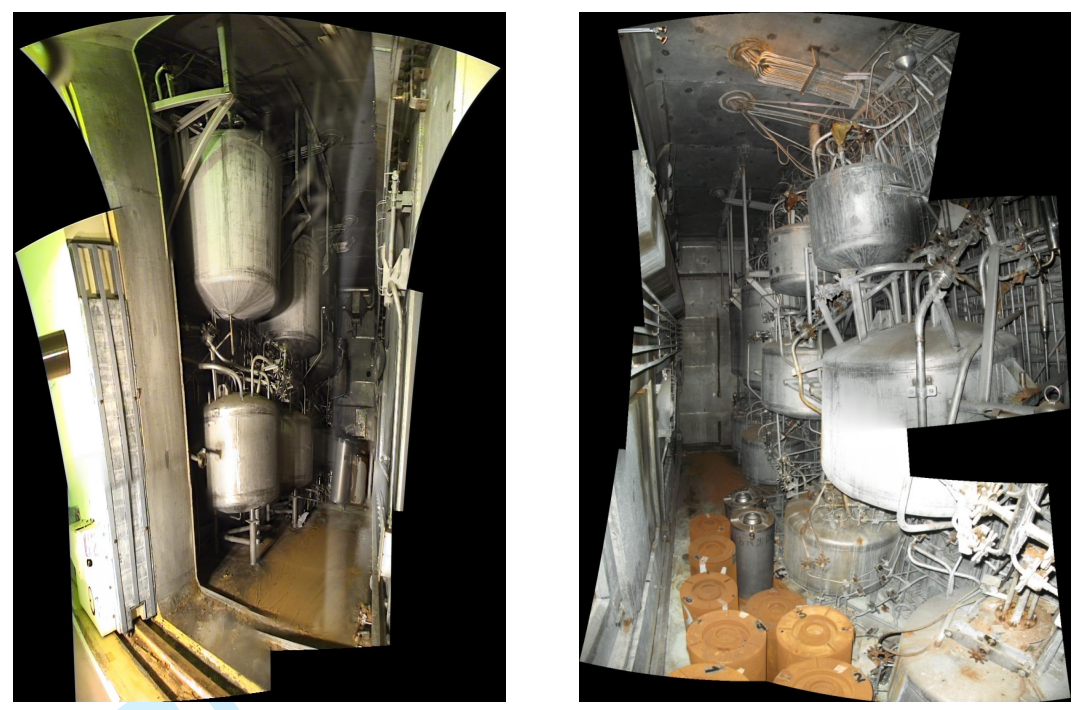

Figure 8: Marcoule Pilot Workshop - View of the cell from outside (left) and inside (right)

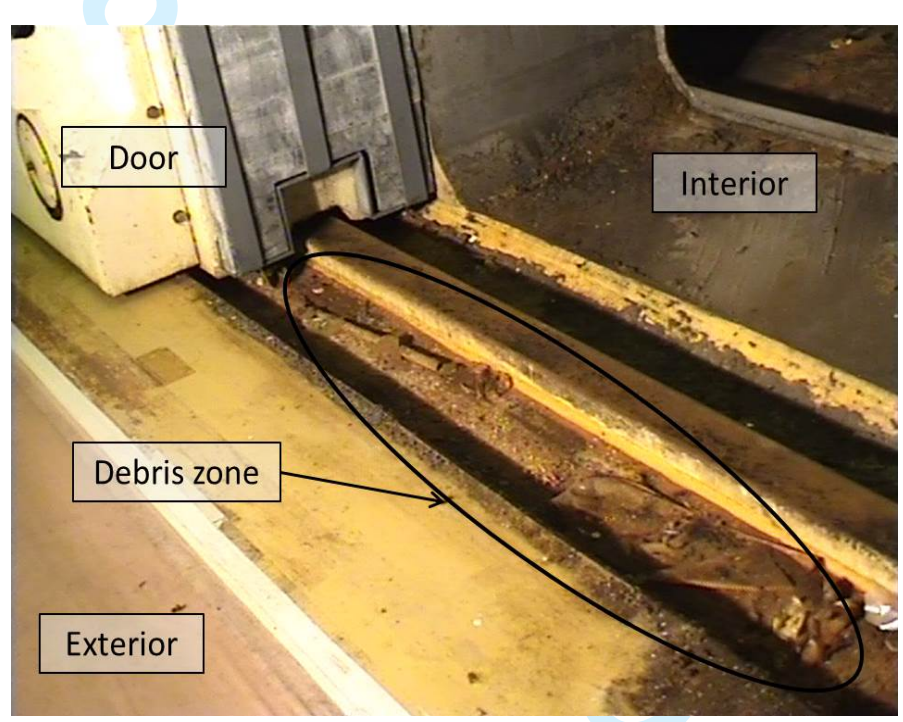

Figure 9: Cell 62 threshold
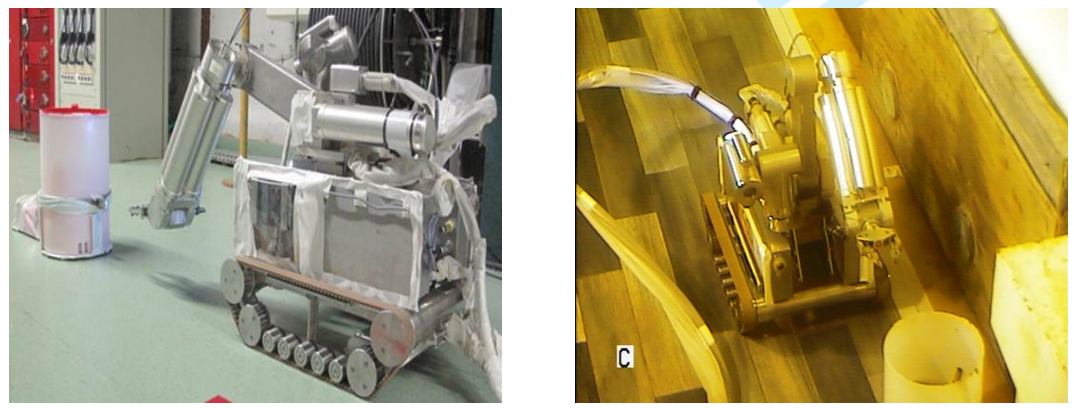

Figure 10: RICA robot ready for the clean-up task. Before the mission began (left) and in front of the cell door (right) 
was placed in the container, the RICA could take it to the storage area used for this type of waste. The piloting cameras and the Romain 50 arm camera enabled the robot to be guided as close as possible to the intervention site. Next, the camera on the gripping tool was used to ensure safe handling of the waste items and to place them into the container (see Figure 11). The debris retrieved was then classified as intermediate
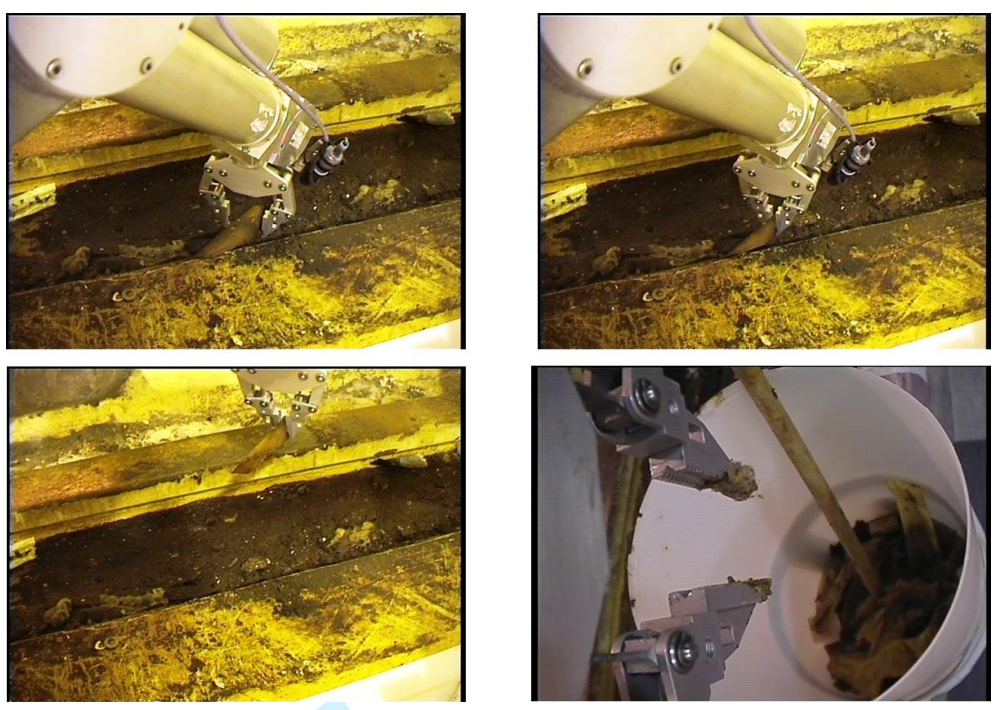

Figure 11: Romain 50 arm working on the cell threshold

level waste and stored appropriately. The average dose rate during the mission was $7.2 m G y \cdot h^{-1}$ and the accumulated dose was $18 \mathrm{mGy}$ for a task lasting 1.5 hours. This example illustrates the RICA robot's ability to collect small-sized samples in zones where human manual intervention cannot be undertaken.

\subsubsection{Temperature taken on an overheated water valve}

The Romain 50 arm is a tool which can also be used to carry measurement detectors as close as possible to a zone of interest. A temperature measurement which needs to be taken in contact with a fitting or structure is an example of this kind of situation. To do so, a temperature detector was attached to a metallic support which could be manipulated by the gripper on the Romain $50 \mathrm{arm}$. The RICA robot could then be used to position the detector close to the zone where the temperature had to be measured (Figure 12). In this case, the task consisted of taking the temperature on an overheated water pipe, in particular on one of the system's valves. The camera attached to the arm's gripper tool was then used to make sure of the exact positioning,

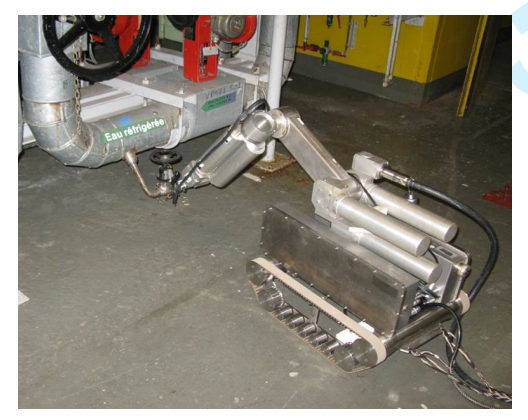

Figure 12: RICA robot equipped with a temperature detector during an intervention

and a time-course temperature evolution curve could be recorded (Figure 13). The temperatures measured varied between $28^{\circ} \mathrm{C}$ (ambient temperature) and $121.9^{\circ} \mathrm{C}$ (valve temperature). This mission illustrates how 

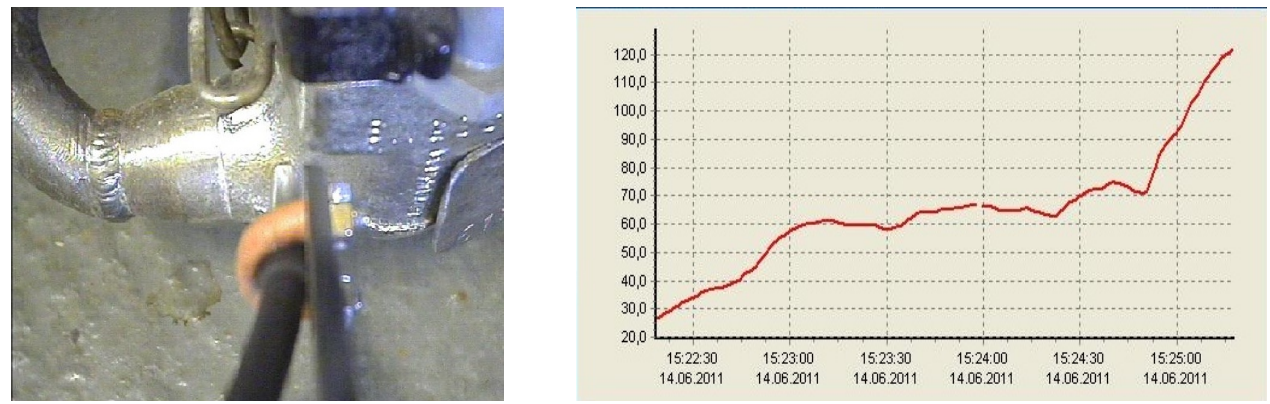

Figure 13: Image sent back by the gripper camera (left). Time-course temperature evolution curve (right).

it is possible to use the RICA robot to carry out contact measurements, as long as the measurement detector is suitably adapted to use with the Romain $50 \mathrm{arm}$.

\subsection{Radiological measurements on an irradiating waste drum}

In this section, we describe a mission which required the use of the RICA robot equipped with a radiological measurement unit. The task was performed in a room where irradiating waste drums are stored. The waste drums mainly contain $\alpha$ emitters, and the waste is categorized as being short-lived low and intermediate level or long-lived intermediate level. The room has several bays and the radiological measurements had to be carried out on a drum located in the last bay, furthest from the door. The photos show the RICA entering the room and moving towards the back of the room. Once it reached the last bay, the robot was positioned facing the waste drum which was to be characterized (see Figure 14). Its navigation within the
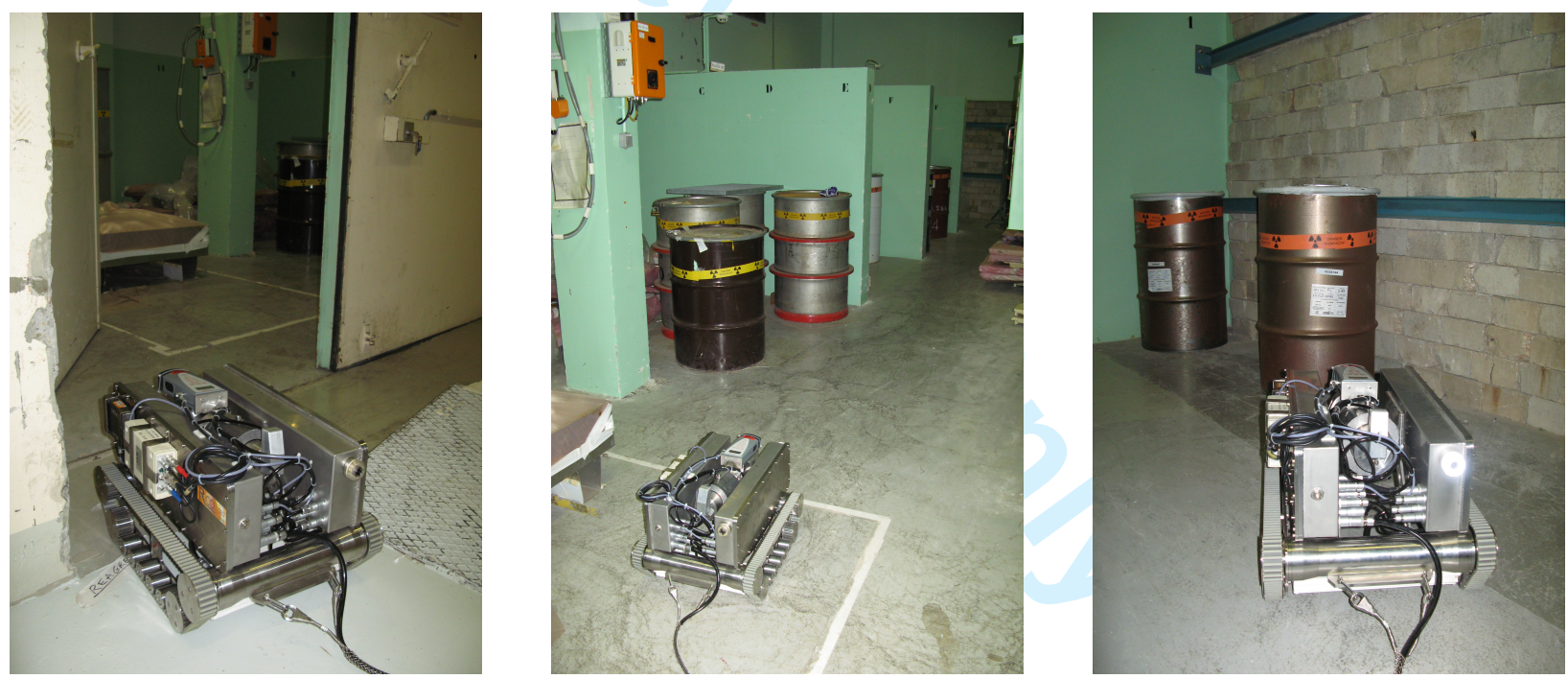

Figure 14: RICA entering (left) - advancing (center) - positioning in front of a drum (right)

room was aided by the telemeter to ensure the robot was accurately positioned. A color camera also helped the operator to position the machine as well as possible in front of the target drum. The use of a dose rate measurement detector associated with that of the telemeter gave a representation of the spatial distribution of the dose rate within the room. In Figure 15, the video return from the color camera shows the position of the telemeter laser. During the operation, the operator can also check the robot's distance from the telemeter laser point laser, the equivalent dose rate and the accumulated equivalent dose. Here, Figure 15 indicates that the RICA robot is located at a distance of $4.40 \mathrm{~m}$ from the telemeter laser pointer laser. At this distance from the wall, an equivalent dose rate of $114.5 \mu \mathrm{Sv} \cdot \mathrm{h}^{-1}$ and an accumulated equivalent dose of 


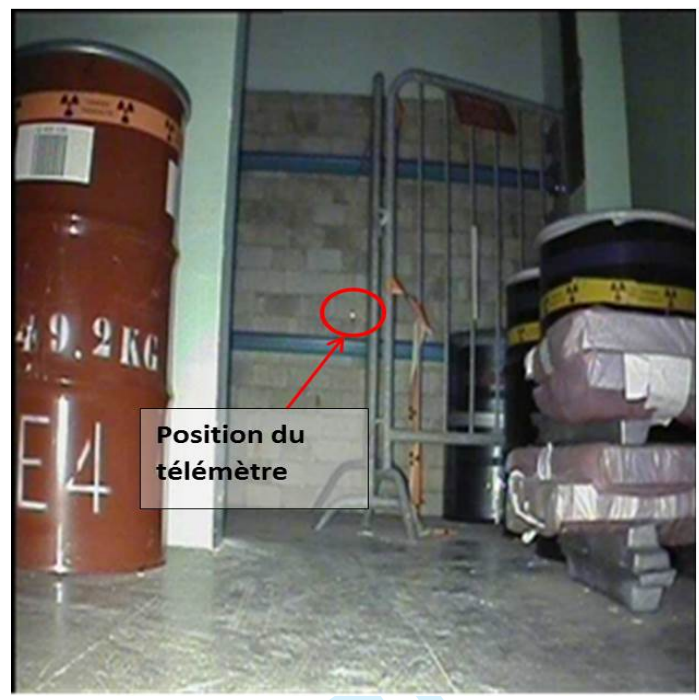

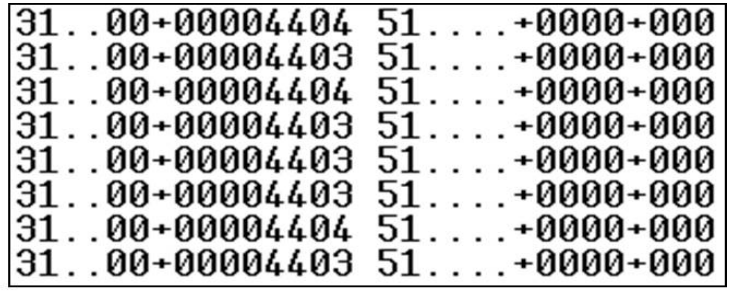

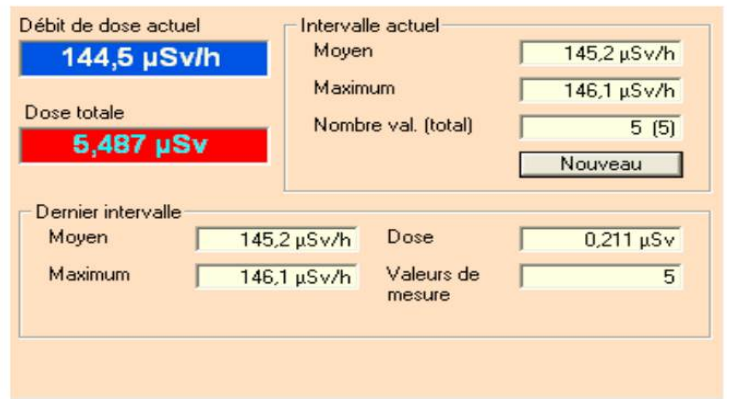

Figure 15: Color video return with laser telemeter position (left). Values for the distances measured by the telemeter (top right). Dose rate and accumulated dose (bottom right)

$5.487 \mu S v$ were measured at that instant. When the RICA was suitably positioned facing the drum to be characterized, with maneuvers particularly based on the telemeter measurements, the ambient dose rate level was checked, giving the data shown in Figure 15. This dose rate measurement was important to determine the appropriate measurement time for the gamma camera and the pose time needed to obtain a satisfactory image. The operator receives three views of the zone to be mapped: a visible image, a composite image, and a gamma image. The composite image is obtained by filtering the gamma image superimposed on the visible image, which enables a colored view of the radiological distribution for a scene to be obtained. Figure 16 shows the three types of images obtained for a drum located at a distance of $1 \mathrm{~m}$ with an ambient dose rate of $125.3 \mu S v \cdot h^{-1}$. It can be seen that there is a dose rate concentration towards the bottom of the drum, and a non-homogeneous distribution within it. Gamma spectrometer detector measurements were
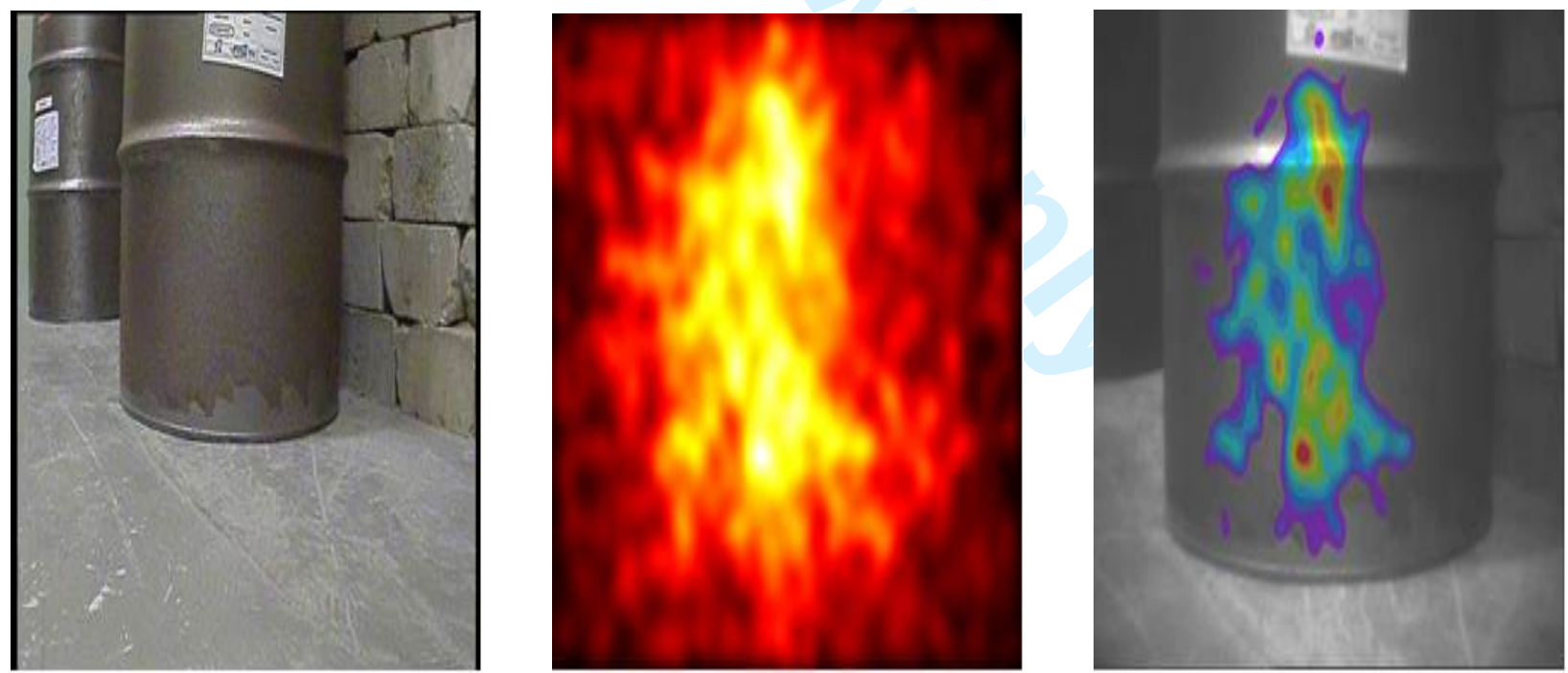

Figure 16: Gamma camera acquisition: visible image (left) - gamma image (center) - composite image (right)

used to quantify the activity distribution in order to be able to interpret the spectrum obtained. In this case, the result indicated that the main contribution to the gamma spectrometry came from the element 
Cesium-137. This example illustrates a possible use of the radiological measurement unit. It is possible to obtain three sets of radiological data at the same time during one characterization mission: the ambient dose rate, the radiological distribution within an irradiating container, and finally the identification of the radioactive elements present.

\section{Conclusion}

This article has described THE RICA robot developed by the CEA and CYBERIA that combines a remotelypiloted mobile platform with different sets of tools to facilitate the investigation of places which have so far been difficult to access, and which safety reasons render inaccessible to human, however well protected. The RICA robot was initially developed to meet characterization needs for nuclear facilities preparing for dismantling operations. This robot's innovation lies in that right from the beginning, it was designed to be able to carry a complete set of radiological measurement instruments in a single unit. This measurement unit enables a full radiological characterization of a facility by supplying all the data necessary to describe the initial state, prior to setting up intervention scenarios. Depending on the information needed, the RICA equipped with the Romain 50 arm can take samples or perform contact measurements via an on-board detector. The development of a single coaxial cable tether for the transmission of different electrical power levels to the machine and for the return of the data acquired is a key point in optimizing all communication with the robot without handicapping its movement capabilities. Even if the RICA robot was first developed for nuclear facility dismantling activities, it could obviously have advantages for visual and radiological investigation tasks following accidental situations. Today, the RICA robot's future prospects mainly lie in the development of a carrier which will be able to overcome more difficult obstacles, and particularly in the development of a hybrid platform.

\section{Acknowledgments}

We would like to thank TRAD whose action with regard to irradiation testing was very helpful. 


\section{References}

Andrieu, C., Olivier Dehaye, C., Tardy, F., Boisserie, T., Desnoyers, Y., Thierfeldt, S., Martin, N., Efraimsson, H., Haakansson, L., Larsson, A., et al. (2013). Radiological characterisation for decommissioning of nuclear installations-final report of the task group on radiological characterisation and decommissioning (rcd) of the working party on decommissioning and dismantling (wpdd)-final report, september 2013. Technical report, Organisation for Economic Co-Operation and Development, Nuclear Energy AgencyOECD/NEA, Working Party on Decommissioning and Dismantling-WPDD, Le Seine Saint-Germain, 12 boulevard des Iles, F-92130 Issy-les-Moulineaux (France).

Bogue, R. (2011). Robots in the nuclear industry: a review of technologies and applications. Industrial Robot: An International Journal, 38:113-118.

Bruzzone, L. and Quaglia, G. (2012). Review article: locomotion systems for ground mobile robots in unstructured environments. Mechanical Sciences, 3:49-62.

Carcreff, H. and Thellier, G. (1995). Method for localizing the radiation source in real time. French Patent EP0674188 A1.

Cybéria (2015). CYBERIA company web site. http://www.cyberiasite.com, consulted in May 2015.

Cybernetix (2015). CYBERNETIX company web site. http://www.cybernetix.fr, consulted in May 2015.

Détriché, J. (1995). Télémanipulation et robotique mobile au CEA: Robotique et téléopération. Revue générale nucléaire, 3:213-220.

Ducros, C., Girones, P., Jonquet, E., and Falciola, J. (2009). Véhicule d'inspection téléguidé pour la localisation et la mesure de sources radioactives. French Patent FR2925702, 2009.

Fougeres, P., Siffert, P., Hageali, M., Koebel, J., and Regal, R. (1999). Cdte and cd1-xznxte for nuclear detectors: facts and fictions. Nuclear Instruments and Methods in Physics Research Section A: Accelerators, Spectrometers, Detectors and Associated Equipment, 428:38 - 44.

Gal, O., Izac, C., Jean, F., Lainé, F., Lévêque, C., and Nguyen, A. (2001). Cartogam - a portable gamma camera for remote localisation of radioactive sources in nuclear facilities. Nuclear Instruments and Methods in Physics Research Section A: Accelerators, Spectrometers, Detectors and Associated Equipment, 460:138-145.

Girones, P., Boisset, L., and Ducros, C. (2013). First report from an advanced radiological inventory for a spent fuel reprocessing plant. Decommissioning Challenges: An Industrial Reality and Prospects, 5th International Conference, April 2013, Avignon, France.

Girones, P., Ducros, C., Lebrun, D., and Berenger, B. (2008). Methodology applied to the waste management study for the dismantling project of apm (reprocessing power plant). Decommissioning Challenges: An Industrial Reality, September-Obtober 2008, Avignon, France.

Guarnieri, M., Kurazume, R., Masuda, H., Inoh, T., Takita, K., Debenest, P., Hodoshima, R., Fukushima, E., and Hirose, S. (2009). Helios system: A team of tracked robots for special urban search and rescue operations. In Intelligent Robots and Systems, 2009. IROS 2009. IEEE/RSJ International Conference on, pages 2795-2800. IEEE.

Lamadie, F., Brenneis, C., Girones, P., and Barras, S. (2006). Dispositif limitant l'apparition d'artefacts de décodage pour gamma caméra à masque code. French, Patent WO2006111678, October, 26, 2006.

Lamadie, F., Gironès, P., Goaller, C. L., Mahé, C., Kohler, J., and Risser, M. (2007). Recent achievements for in-situ measurements: Applications to an actual decommissioning project. Waste Management 2007 Symposium, March 2007, Tucson, Arizona, USA.

Le Goaller, C. (2006). Dispositif d'imagerie gamma amélioré. French, Patent WO2006090035, August, 31, 2006. 
Le Goaller, C. and Mahe, C. (2009). Dispositif d'imagerie gamma amélioré permettant la localisation de sources irradiantes dans l'espace. French, Patent WO2009153229, December, 23, 2009.

Moore, T. (1985). Robots for nuclear power plants. IAEA Bulletin, 27(3):31-38.

Morisono, R. (2013). Development of investigation robot "FRIGO-MA" for reactor buildings in Fukushima Daiichi nuclear power station. Workshop on Robotics and Automation in Nuclear Facilities, IEEE/RSJ International Conference on Intelligent Robots and Systems, November, 2013, Tokyo, Japan.

Nagatani, K., Kiribayashi, S., Okada, Y., Otake, K., Yoshida, K., Tadokoro, S., Nishimura, T., Yoshida, T., Koyanagi, E., Fukushima, M., et al. (2011). Gamma-ray irradiation test of electric components of rescue mobile robot Quince. In Safety, Security, and Rescue Robotics (SSRR), 2011 IEEE International Symposium on, pages 56-60. IEEE.

Nagatani, K., Kiribayashi, S., Okada, Y., Otake, K., Yoshida, K., Tadokoro, S., Nishimura, T., Yoshida, T., Koyanagi, E., Fukushima, M., and Kawatsuma, S. (2013). Emergency response to the nuclear accident at the fukushima daiichi nuclear power plants using mobile rescue robots. Journal of Field Robotics, $30: 44-63$.

Nagatani, K., Yoshida, K., Kiyokawa, K., Yagi, Y., Adachi, T., Saitoh, H., Suzuki, T., and Takizawa, O. (2008). Development of a networked robotic system for disaster mitigation. In Field and Service Robotics, pages 453-462. Springer.

Saphymo (2015). SAPHYMO company web site. http://www.saphymo.fr, consulted in May 2015.

Seward, D. W. and Bakari, M. J. (2005). The use of robotics and automation in nuclear decommissioning. In 22nd International Symposium on Automation and Robotics in Construction ISARC.

Thomas, J.-C., Beutier, T., Pourrouquet, P., Peyrard, P.-F., Lavielle, D., and Chatry, C. (2008). Fastrad: A 3D CAD interface for radiation calculation and shielding. In Proc. 11th Int. Conf. Radiation Shielding, $I C R S$.

TRAD (2015). TRAD company web site. http://www.trad.fr, consulted in May 2015.

Tsukui, S. and Akazawa, T. (2013). Development of survey runner. Workshop on Robotics and Automation in Nuclear Facilities, IEEE/RSJ International Conference on Intelligent Robots and Systems, November, 2013, Tokyo, Japan.

Walker, V. and Wadsworth, D. (2012). Needs for robotic assessments of nuclear disasters. Transactions of the American Nuclear Society, 106:947-948.

Wolicki, E. A., Namenson, A., and Carlan, A. (1995). Guidelines for developing radiation hardness assurance device specifications. Technical report, DTIC Document.

Yamauchi, B. M. (2004). Packbot: a versatile platform for military robotics. In Defense and Security, pages 228-237. International Society for Optics and Photonics. 